Welt nicht mehr zu entbehren, - Ebensfalls durch Horns tätigste Werbung kamen 1926 die „Wanderversammlungen der deutschen Entomologen:" zustande, deren Teilnehmerzahl ständig gewachsen ist. Ein Beweis, daß auch diese Schöpfung lebensfähig ist und notwendig war.

Die größten, bleibenden Verdienste hat sich Horn um die Schaffung und den Ausbau des ,Deutschen Entomologischen Institutes der Kaiser-Wilhelm Gesellschaft" erworben. Dieses Institnt hat wechselvolle Schicksale erlitten. Ursprünglich von Kra atz als „Deutsches Entomologisches Nationalmuseum" 1886 begründet, erhielt es später den Namen ,.Deutsches Fntomologisches Museum" und wurde 1922 von der Kaiser-Wilhelm-Gesellschaft mit dem jetzigen Namen übernommen. Seit 1904 war Horn stellvertretender und später leitender Direhtor. Auf Grund seiner weltweiten persönlichen Beziehungen gelang es reichste Schätze an Sammlungen und Literatur in dem Institute $\mathrm{zu}$ vereinigen. Durch unermüdliche Tätigkeit gelang es Horn die Bibliothek auszubauen, so dal sie heute die größte eutomologische Fachbibliothek des europäiscben Kontinents ist. Schon währead der Kriegszeit und vor allen Dingen in der Inflationszeit wal der Bestand des Entomologischen Institutsin Dahlem mohr als einmal aufs schwerste gefährdet, aber Horn verstand es mit bewunderungswürdigem Geschick und mit erstaunlicher Zähigkeit alle Schwierigkeiten zu ïberwinden und dank seiner vielen Beziehungen war es auch möglich, immer wieder Geldquellen zu erschließen, so daß das Ganze erhalten werden konnte. Horn hatte bald sehr klar erkannt, daß auf die Dauer ein Bestand dieser entomologisehen Sondereinrichtung nur möglich wäre, wenn die rein musealen Ziele mit anderen Zielen verknüpft würden. Schon vor dem Weltkrieg war Horn mit den Entomologen der Biologischen Reichsanstalt in nähere Verbindung gekommen und nach dem Kriege wurde die Verbindung besonders eng. Damit stellte H or n sein ganzes Institut und vor allem die Bibliothek und den umfangreichen Auskunfts- und Ermittlungsdienst auch in den Dienst der angewandten Entomologie, so daf alle Institute oder Einrichtungen, die heute in Deutschland sich mit angewandter Fntomologie beschäftigen, gleichsaın eine gemeinsame Bibliothek besitzen, und einen Auskunftsund Ermittlungsdienst benutzen könnea, wie er ohne die Hornschen Vorarbeiten überhaupt nicht zu schaffen gewesen wäre. Gerade die Auskunft und Ermittlung ist die Frucht der jahrzehntelangen Bemühungeu von Horn mit Entomologen und Sammlern der ganzisn Welt Verbindungen anzuknüpfen und freundschaftlichst zu unterhalten. 1925 hat das Reichsministerium für Ernährung und Landwirtschaft einen Teil des Institutsetats übernommen und seit 1934 besteht eine "Arbeitsgemeinschaft der Biologischen Reichsanstalt und des Deutschen Entomologischen Institutes". Damit ist einerseits die $\mathrm{Zu}$ kunft dieser Schöpfung gesichert und andererseits der deutschen angewandten Entomologie eine Arbeitshilfe von unersetzlichem Werte zur Verfügung gestellt worden.

Horn war unermüdlich, sein umfangreiches entomologisches Allgemeinwissen, die erstaunliche Kenntnis der entomologischen Literatur und auch seine persönlichen $\mathrm{Be}$ ziehungen zu den namhaftesten Entomologen der Welt allen denen zurVerfügung zu stellen, die sich an ihn wandten. Wenn jemand eine Sache um ihrer selbst willen getan hat, so war es hier der Fall.

Persönlich war Horn allen Äußerlichkeiten abhold; als Beispiel sei nur angeführt, daß er stets den Professortitel ausgeschlagen hat. Er lebte seiner Wissenschaft und seinem Institute, und die, Sorge um dieses hat ihn bisweilen zermürbi und sogar aufs Krankenlager geworfen. Aber alles in allem! Er hat eine Schöpfung hinterlassen, die noch auf viele Jabrzehnte hinaus zum uneutbehrlichen Rüstzeug der Entomologen der Welt gehören wird. Für alles danken wir ihm übers. Grab hinaus. Albrecht Hase, Bln.-Dahlem.

\title{
Mitteilungen aus der Deutschen Gesellschaft f. angew. Entomologie E.V.
}

\section{Mitgliedsbeiträge}

Die Mitglieder werden ersucht, die Jahresbeiträge einsenden zu wollen. Zahlstelle: Commerz- und Privatbank, Fil. Gießen [Hess.]. Postscheckkonto der Bank: Postscheckamt Frankfurt a. M. Nr. 19330. Der Beitrag beträgt für persönliche Mitglieder 10 RM., für korporative 30 RM.

\section{Neues Mitglied}

Vollert, Hans-Eberhard, Berlin-Grunewald, Hohenzollerndamm 111. 